\title{
POESIA AMERICANA, 1913-1973: AS DUAS REVOLUÇOES
}

\section{James Guimond **}

No início da década de 60 . ocorreu o triunfo da revolução na linguagem poética, que foi iniciada por Walt Whitman em 1855 quando da publicação de sua obra Leaves of grass. Esta revoluçāo poética teve seu início há mais de cem anos, e foi transportada ao início do século XX por um número de poetas - notadamente Ezra Pound, Carl Sandburg e William Carlos Williams. Contudo, apenas na década de 50 e no início da de 60 é que esta revolução tornou-se realidade, e seus princípios começaram a dominar a poesia norte-americana. Foi, então, no início da década de 60 , que alguns discipulos e seguidores de Williams e de Pound - principalmente Charles Olson. Robert Creeley, Denise Levertov, Allen Ginsberg e (não tão destacadamente) Robert Lowell - fizeram com que fosse aceito e até mesmo apreciado, o fato dos poctas escreverem seus poemas na língua vernácula, sem rimas e sem a métrica inglesa. Entretanto, apenas estabelecida a predominância dos princípios poéticos de Whitman, Pound, Williams e Olson, houve uma segunda revolução poética. Esta revoluçāo que começou no início e meados da década de 60 , tinha sido liderada principalmente por Robert Bly e James Wright. Ela não repudia as premissas lingüisticas da revolução poética de Whitman, Pound, Williams, Olson e Crecley. Bly, Wrigh e seus seguidores nāo usam rima nem métrica. Porém, os poetas que estão criando esta segunda revolução poética durante as décadas de 60 e 70 exigem que a poesia norte-americana tenha conteúdos poéticos completamente diferentes - que ela seja muito mais mística e surrealista, que diga respeito

* Traduçáo do Inglés por Cecilia Iness Erthal, Auxillar de Ensino de Lingua e Literatura Inglesa do Departamento de Letras Estrangeiras Modernas, da Unlversidade Federal do Paraná, e sluna do Curso de Pór-Graduação em Letras da mesma Universidade.

* James Guimond é PhD em Literatura Norte Americana (USA) com a tase The Art of William Carlos Williams, defendida em 1965 e publicada en 1968 pela University of Illianois Press. Publicou, também, William Carlos Williams and the Past (in Journal of Modern Liternture, 1971) e After Imagism (In Ohio Review, 1973). Atualmente leciona Literatura Inglesa na RIder University em Lawrenceville (USA). 
mais a sonhos, à fantasia, c ao que Bly se refere como sendo o "mundo interior".

A difcrença entre os objetivos destes dois grupos de revolucionarios poéticos foi muito bem sintetizada pelo poeta contemporâneo Charles Simic. "Parece-me que", Simic disse numa entrevista em 1973.

o fato mais importante acerca da poesia (norte) americana do século XX, serna a realização da geraçāo do início do século, especialmente William Carlos Williams e Pound, que encontraram um idioma nativo que separou a poesia americana da tradiçāo inglesa. Em outras palavras, nós começamos a escrever em nossa própria língua... (No entanto), há ainda um outro problema. ainda uma outra exigência para termos uma literatura completamente nativa... descobrir as raízes da imaginaçāo local, isto é, a maneira pela qual o americano pensa e sonha. 1

A justificativa para a revolução poética de Whitman foi exposta, em 1844, por Emerson, no seu ensaio The poet. "Nós nāo nos en-! doreçamos à vida com clareza e profundidade suficientes, nem cantamos a nossa própria época e nossas condiçōes sociais". Emerson queixou-se aos seus contemporâneos.

... Nós ainda năo tivemos na América. gênios com olhos tirànicos. que conhecessem o valor dos nossos materiais incomparáveis... Todavia a América é um poema aos nossos olhos; sua ampla geografia ofusca a imaginação e ela não vai esperar pela métrica. ${ }^{2}$

O nacionalismo de Whitman era até mesmo mais impetuoso do que o de Emcrson. "Dentre todas as naçöes da face da terra e em qualquer época, os americanos sāo os que, provavelmente, têm natureza poética em grau mais elevado", disse no Prefácio da ediçāo de 1955 de !Leaves of grass. 3 "Os próprios Estados Unidos sāo, na sua essência o maior poema". O nacionalismo de Whitman também justificou a sua rejeição ao passado. às formas poéticas inglesas na sua poesia e o uso de linguagem coloquial e do verso livre rítmico. Mas, apesar de cle ter dito no Prefácio da edição de 1855 que "a língua inglesa compartilhava amigavelmente da grande experiência amcricana", 4 em Leaves of grass ele rejeita as formas da poesia in-

1 An intervlew with Charles Simic. Ohio Review, Athenas, 14:52. Winter 1973.

2 EMERSON, $R$. $W$. The poet. In: - The complete essays and other writings. New York. The Modern Library. 1940. p. 338.

3 Brooklyn. N.Y.. 1855, p. til.

4 Ibld. n. $x i$. 
glesa para poder compor seus poemas de acordo com a "métrica" nativa americana quc Emcrson almejava. A revoluçāo poética de Whitman foi, de um modo geral, ignorada durante o século XIX e início do século XX. Tanto os seus temas quanto a sua forma poética em verso livre, foram considerados excentricidades pessoais.

Os poetas mais respeitados durante a primeira metade do século $\mathrm{XX}$ - Eliot. Frost e Stevens - foram todos muito mais conservadores do que Whitman no que diz respeito à linguagem poética e ao estilo. Embora tenham incorporado na sua poesia os ritmos da fala do século XX, frequentemente usaram a rima e jambos ou outra métrica tradicional inglesa.

Além disso. o tom intelectual e emocional que dominou a pocsia norte-americana atć os anos 50 era bem diferente daquele tom vigoroso que Whitman chamava de seu "grito bárbaro". Devido ao exemplo estabelecido particularmente por Eliot e Auden. foi gradativamente introduzida o que Donald Hall descreve como "ortodoxia que prevaleceu" na poesia norte-americana entre 1925 e 1955.

Foi, diz Hall, "uma ortodoxia... originada da autoridade de T. S. Eliot e dos novos críticos; ela se manifestou através das publicaçōes literárias trimestrais e das Universidades. Queria uma poesia simétrica, intelectual, irônica e espirituosa". 5

A alternativa principal para esta "ortodoxia" foi o Imagismo, um moviunento poético iniciado em 1913 por Ezra Pound e alguns poetas ingleses e americanos, incluindo H. D. Amy Lowell. William Carlos Williams e alguns outros. Os princípios dos Imagistas, como foram descritos por Pound, enfatizaram mais o tratamento direto e a vivacidade do que a ironia e a espirituosidade. Pound descreve que o primeiro "princípio em que concordaram foi o tratamento direto da "coisa" quer subjetivo ou objetivo", e definiu uma "imagem" como sendo "aquilo que apresenta um complexo intelectual e emocional num mesmo instante". 6 Em outras palavras, o poema não deveria ser deliberadamente trabalhacio, irônico e espirituoso - mas, ao invés. deveria ser econômico, direto, vívido e instantâneo.

Os princípios dos Imagistas, de acordo com a formulaçāo feita por Ezra Pound, não proibiam o uso da rima e métrica inglesas tradicionais; mas enfatizavam que outras considerações eram mais importantes. "No que diz respeito ao ritmo", disse Pound, "...componha na seqüência da frase musical, não na seqüência do metrônomo". Isto significava, como Pound claramente explicou, "Não retalhe o scu material em jambos separados. Nāo faça cada linha acabar ao seu final para então começar cada linha seguinte com novo fólego. Aconselhou o poeta a saber muito sobre assonância, aliteração $e$ rima; mas

5 IIALL, Donald. Contemporary American poetry. Rev. ed. Baltimore, Penguin, 1972. p. 25.7 .

6 POUND. Ezrn. A retrospect. In: - Literary ousays. New York, New Directions. 1954. p. 3. 
disse então que "ć possivel que o artista raramente precise" deste conhecimento. Elc também comentou que apesar "das formas mais simétricas terem certos usos... um grande número de assuntos não pode ser expresso com precisāo e, portanto. com adequaçāo através das formas simétricas.7 Consequentemente, a Teoria do Imagismo de Pound permitiu ao poeta escrever poemas em verso livre; e na prática, os Imagistas realmente escreveram a maior parte de seus poemas em verso livre.

o Imagismo não durou muito como movimento. Pound e Lowell dividiram o grupo em dois quando discordaram a respeito dos padrões que deveriam ser usados nas antologias Imagistas. Alguns dos Imagistas acabaram tornando-se (ou permaneceram) poetas medíocres. Outros abandonaram completamente a poesia, e o próprio Pound tornoul-se gradativamente tão obscuro poeticamente e tāo controvertido politicamente, que não foi mais um representante muito útil para qualquer movimento poético.

Foi, provavelmente, Williams quem mais provocou $e$ finalmente derrubou a "ortodoxia" que Hall descreve. Ele permanece fiel aos princípios básicos do Imagismo ao longo de sua carreira. em que coerente e rigorosamente exigiu que a poesia devesse ser escrita "na sequiencia da frase musical", sem jambos, e que deveria ser "direta" im seu tratamento temático.

Embora finalmente tenha adotado uma espécie de padrāo métrico chamado "pé variável", ele insistiu $\mathrm{cm}$ que a poesia norte-americana devesse ser escrita sem os padrōes métricos ingleses para que mantivesse a máxima fidelidade à língua falada. Em sua Autobiografia, disse que a poesia existe na própria lingua "que nós ouvimos durante tocia a nossa vida", nas "palavras reais que ouvimos em todas as situaçōes... Está realmente lá, na vida diante dos nossos olhos, em todos os minutos em que estamos ouvindo... não na nossa imaginaçāo, mas lá. de fato lá". $8 \mathrm{E}$, também. da maneira que um poema como "Queen-Ann's-Lace" (cscrito em 1921) mostra, ele foi escrupulosamente fiel aos princípios Imagistas de tratamento econômico e "direto" do tema.

No entanto, atć os anos 50 , Williams foi uma figura um tanto isolada e solitária na poesia americana. Até entāo. os seus livros de poesia foram publicados ou as suas próprias custas, ou pela Com. panhia Editora New Directions, que foi, sem dúvida, a editora mais radical dos Estados Unidos durante as décadas de 30 e 40 . O fato de ele ter usado verso livre foi interpretado pela maioria dos críticos e revisores como sinal de excentricidade pessoal ou de impropriedade poética. Embora ele tenha recebido algumas honras e louvores dos

7 POUND, p. 3.6.

8 Williams, William Carlos. Autobiozmphy. New York, Random House. 1951. p. 362 . 
seus companheiros de carreira poética, suas vendas eram pequenas; e era raramente convidado a dar palestras ou a ler poemas ou a receber títulos honorificos de Universidades.

Durante os anos 50, no entanto, os padröes poéticos começaram a mudar nos Estados Unidos, quando tornou-se evidente que muitos e bons poetas jovens estavam escrevendo mais à maneira de Williams e Cummings e Pound do que à maneira de, digamos, Frost. Eliot, Auden ou Stevens. Primeiro havia os "beat poets" como Ginsberg e Ferlinghitti. Depois surgiram alguns "convertidos" importantes, particularmente Denise Levertov e Robert Lowell - que mudaram as métricas ortodoxas para uma linguagem poética mais idiomática por zausa da influência de Willianıs. Ao mesmo tempo, no início da década de 50 , um outro grupo de poetas chegou a compreender os princípios poéticos de William (de Pound e também de E. E. Cummings) tanto na teoria quanto na prática.

Estes poetas são frequentemente chamados de "Black Mountain Poets" porque muitos deles tinham lecionado ou estudado na Faculdade Black Mountain, uma Universidade experimental da Carolina do Norte, que foi um fracasso financeiro, mas um sucesso artístico. $O$ pocta Charles Olson, que foi reitor da Black Mountain por certo tempo, fez o possível para transformar a prática poética de Williams num conjunto de normas poéticas. Ele considerava a "respiração" o ritmo real da fala, como sendo o elemento mais importante na poesia; e insistia em que a poesia devesse reproduzir a "respiraçāo" com a máxima fidelidade. Ela poderia reproduzi-la, argumentava em seu ensaio "Projective Verse" de 1950, por causa do modo pelo qual os poetas usavam a máquina de escrever. "Devido a sua rigidez e à precisāo no espaçamento", disse, "a máquina de escrever.

pode indicar, para um poeta, exatamente a respiração, as pausas, as suspensōes até mesmo de sílabas, justaposiçōes até mesmo de partes de frases, que ele pretende. Pela primeira vez o poeta tem a pauta musical e o compasso que o músico já tinha. Pela primeira vez, cle pode, sem a convenção de rima e métrica, gravar o que ele ouve da sua própria fala e... indicar como ele gostaria de que qualquer leitor, silenciosamente ou não, declamasse sua obra. ${ }^{9}$

Robert Creeley expôs o mesmo princípio cm 1953, quando escreveu que o poeta deveria "estruturar... suas palavras na página" para que suas colocações [das palavras] permitissem [ao leitor] lê-las com sua própria voz, exatamente como pretendia o poeta e assim dar ao "poema todo o seu impacto de fala". 10

9 oLsON, C. Projective verse. In: - Selected writlnge. New York, New Directions, 1966. p. 22.

10 CREELEY, R. A note on poetry. In: - A quick sraph. San Fran. cisco, The Four Seasons Foundation, 1970. p. 27. 
Quanto a Williams. ele estava tão satisfeito com as idéias de Olson e de seus seguidores que publicou parte do ensaio (de Olson) "Projective Verse" como um dos capitulos finais de sua "Autobiografia". Em outras palavras, aceitou o ensaio de Olson como complementaçāo e justificativa da sua própria carreira como poeta.

Whitman tinha começado a revoluçāo do verso livre na poesia norte-americana um século antes, em 1855, quando publicou Leaves of grass. Mas, apenas na década de $1950 \mathrm{e}$, principalmente, por influência de Williams, Pound e Cummings que esta revolução foi finalmente bem sucedida. Só entāo foi possivel para um poema como "I know a Man" de Creeley, ser publicado e lido sem ser considerado extravagante, estranho e excêntrico. Esperava-se agora que o poeta usasse sua linguagem coloquial com a máxima fidelidade, para quebrar a "linha" do seu poema, rigorosamente em concordância com o ritmo de sua "respiração". Não se esperava que ele fosse irônico, espirituoso ou simétrico.

Mas, ao mesmo tempo. em que a revolução do verso livre estava finalmente se consolidando, uma nova revolução já tinha iniciado. Na última metade da década de 50 , um poeta chamado Robert Bly começou a publicar uma pequena revista $\mathrm{em}$ sua fazenda em Minnesota. No início chamou-a de The Flfties (Os Anos Cinquienta). Quando mudou a década, chamou-a de The Sixtles (Os Anos Sessenta), e atualmente já lançou, no minimo uma edição da chamada The Seventhes (Os Anos Setenta). Nas primeiras c poucas tiragens da sua revista. Bly compartilhava de algumas das preocupaçōes e antipatias de Williams, Pound, Olson e Creeley. Atacou o uso do pentâmetro jâmbico. Condenou a "prolixidade" e a "retórica", e depreciou poemas que tinham cxplanaçōes moralistas e filosóficas. Atacou os novos criticos muito mais diretamente do que Williams e Olson tinham atacado. Mas, ao mesmo tempo, também ridicularizou a tcoria da "respiráąăo" de Olson, e criticou Williams. Pound e os Imagistas por escreverem o que ele chamou de "a poesia de figuras". 11

A atitude de Bly em relação a Williams é ambivalente. Falou muito favoravelmente a respeito de Williams - mas sempre modifica este louvor com a critica de que a poesia de Williams nāo é suficientemente interiorizada ou "espiritual". "Se a poesia americana tivesse um centro, este seria William Carlos Williams, disse cm 1963, mas acrescentou que "a poesia de Williams... mostra uma ausência fundamental de vida espiritual". Mais adiante, no mesmo ensaio, diz que Williams, pessoalmente era agradável - "uma pessoa nobre, o mais bondoso e humano dos poetas de sua "geração", mas de acordo com

11 Veja a nota introdutória de Bly à sua antologia The Lion's tall and eyes. Madison, Minn.. The Slxtles Press, 1962; The Fifties, Madicon. Minn., (2): 13. 36, 45, 1959: The Sixties, Madison, Minn.. (1): 28-9, 1960. 
os padrões de Bly, falta espiritualidade a sua poesia. Os poemas de Williams, ele escreve,

...mostram uma profunda vida emocional, matizada com o ímpeto da inteligência ao tratar de coisas materiais - mas não mostram vida interior, se entendermos por vida interior um interesse pelo engrandecimento espiritual... Williams quer que a poesia se limite a carrinhos-de-mão, tampinhas de garrafa, capim... Permanecer junto à superfície torna-se uma obsessão? 12

A caracterização que Bly fez da poesia de Williams não ¿́, acredito, muito exata, mas expressa realmentc os princípios poćticos do próprio Bly. De acordo com sua opinião, a grande diferença entre a sua presia e a dos Imagistas ou dos "Black Mountain Poets", é que eles querem basicamente comunicar "superfícies" — aparência de imagens c o som das palavras - enquanto Bly quer comunicar acontecimentos psiquicos "interiores".

A análise que Bly faz do poema de James Wright "Lying in a Hammock at William Duffy's Farm" é um bom exemplo de como ele interpreta este tipo de poesia "interiorizada". De acordo com Bly, a mente do poeta, no poema

...parece estar desperta de maneira estranha, sobrenatural. Parece que tudo está apresentado em delícada minúcia. $O$ esterco dos cavalos brilham como pedras alquímicas. 0 poeta se recosta e mergulha em seus pensamentos. $O$ vislumbre de um filhote de falcão o faz lembrar de que nada encontrou de certo na vida; que chegou a nenhum lugar, que ainda está flutuando. A pergunta que um poema nunca faz diretamente é esta: como é possível haver tantos símbolos espirituais, sinais, marcadores de caminho em toda parte, c não obstante o homem que os vê nāo ter chegado a lugar algum, nada ter concluído das tarefas espirituais que aqueles símbolos sugerem? 13

Em outras palavras, as imagens têm relevância incalculável para a vida interior do poeta. As porçōes de esterco que "brilham como pedras douradas" são uma espécie de transmutação alquímica que nāo aconteceu na sua própria vida. O falcão o faz lembrar de que ele está flutuando, de que cle nāo tem objetivo para seus sonhos. Desde que cle não pode transformar sua vida ou dar-lhe uma dircção, sente que a "desperdiçou". Assim, apesar do poema incluir imagens do mundo físico. ele as usa para comunicar experiências do mundo "interior", os pensamentos intuitivos que surgem das profundezas misteriosas de sua mente.

O poema de Bly sobre a noite na Rua Macdougal é um bom exem-

13 Choice, Chigago, (3): 33, 35, 1963.

13 The work of Jumes Wright. The Sixties, Mndison, Minn. (8): 67-8, 1966. 
plo da qualidade surrealista que caracteriza grande parte da poesia desta segunda revoluçāo poética. O poema começa com uma situaçāo concreta e definida. O poeta usa homens gritando num determinado local: Macdougal é uma rua que fica perto da Praça Washington, em Greenwich Village, na cidade de Nova York. Mas, ao invés de descrever os homens, a rua, ou os gritos, Bly transmite os sentimentos a a fantasia que a situação cria no seu interior.

Primeiro ele compara a noite da cidade com a noite do campo. "Os pequeninos aninham-se em suas frias sepulturas", refere-se, acredito, às sementes no solo. No campo há um ritmo natural de escuridāo e luz. frio e calor, vida e morte. Mas na cidade há um ritmo artificial de pessoas que permanecem acordadas durante a noite atć que o "esgotamento vença" sua excitaçāo. Ele. entāo, transmite a idéia de violência e perigo que os gritos despertaram nele - "o trabalho amargo de águas lamacentas".

Aqui o poema torna-se mais misterioso, já que ele menciona que a excitação alimenta as "vozes dos homens brancos". Isto é. a agitação dos homens á aumentada pelo perigo e pela inquietaçāo da cidade; suas vozes "servem de alimento" e seus gritos se tornam mais altos. Mas, por que homens brancos? Talvez estes sejam homens brancos que vieram a rua para lutar contra os negros, ou talvez alguma espécie de briga tivesse começado entre brancos e negros. 0 poema nada mais transmitc cla situação que Bly mencionou no título e nas duas primeiras linhas. Em vez disso. começa a transmitir apenas seus pensamentos e sentimentos interiores.

O final do poema é completamente surrealista. Nele Bly anula o tempo e o espaço, imaginando estar presente na noite em que "o primeiro navio de escravos da Nova Inglaterra" partiu para a América "com os negros no porāo de carga". A imagem nada diz a respeito da Rua Macdougal. mas transmite realmente as próprias sensaçōes de medo e, talvez, de culpa de Bly - a sensação de maldade e de ameaça que os gritos dos homens criaram em sua mente.

No entanto, apesar dos poemas de Bly e Wrigh serem místicos e surrealistas em seus conteúdos, são também bons poemas Imagistas. Eles estão escritos em verso livre. com linhas de comprimento irregular, e sem jambos. Suas imagens sāo concisas, vívidas e dirctas. E seus poemas sāo extremamente precisos e econômicos. Consequentemente, pode-se dizer que os poemas de Bly, Wrigh, e seus seguidores, representam uma revoluçāo mais no conteúdo poético do que na técnica poética. Embora falem injuriosamente dos Imagistas e dos "Black Mountain Poets", os poemas místicos de Bly e Wright estāo na mesma tradiçāo lingüística $c$ foram escritos. essencialmente, com as mesmas técnicas poéticas. Eles diferem de Williams. Creeley e Olson na insistência de que o poema deve ter, também. uma dimensão de "interioridade" mística ou surrealista. 


\section{APENDICE}

\section{Alguns Grupos Poéticos}

1 - Imagistas: Ezra Pound, H. D. (Hilda Doolittle), Richard Aldington, Amy Lowell, F. S. Flint, W. C. Williams.

2 - "Beat Poets": Allen Ginsberg, Gregory Corso, Lawrence Ferlinghetti.

3 - "Black Mountain Poets": Charles Olson, Robert Creeley, Robert Ducan, Edward Dorn, Jonathan Williams, Paul Blackburn. Denise Levertov.

Atualmente, os principais poetas "místicos" dos Estados Unidos são Robert Bly e James Wright; mas as mesmas qualidades deste tipo de imaginação mística podem ser encontradas em alguns dos poemas de poctas como Louis Simpson, Galway Kinnell, Charles Simic, Stephen Berg, e Robert Mezey.

\section{POEMAS}

1 - Lying in a Hammock at William Duffy's Farm in Pine Island, Minnesota

\section{James Wright}

Over my head, I see the bronze butterfly, Asleep on the black trunk, Blowing like a leaf in green shadow.

Down the ravine behind the empty house.

The cowbells follow one another

Into the distance of the afternoon.

To my right,

In a field of sunlight between two pines,

The droppings of last year's horses

Blaze into golden stones.

I lean back, as the evening darkens and comes on.

A chicken-hawk floats over, looking for home.

I have wasted my life.

2 - Hearing Men Shout At Night on Macdougal Street

Robert Bly

How strange to awake in a city,

And hear grown men shouting in the night.

On the farm the darkness wins.

And the small ones nestle in their graves of cold: 
Here is a boiling that only exhaustion subdues.

A bitter moiling of muddy waters

At which the voices of white men feed!

The street is a sea, and mud boils up

When the anchor is lifted. for now at midnight there is about

[to sail

The first New England slave-ship with the Negroes in the hold.

3 - Queen-Ann's-Lace

\section{William Carlos Williams}

Her body is not so white as

anemone petals nor so smooth-nor

so remule a thing. Itis a field

of the wild cariot taking

the field by force; the grass

does not raise above it.

Here is not question of whiteness

white as can be, with a purple mole

at the center of each flower.

Each flower is a hand's span

of her whiteness. Wherever

his hands has lain there is

a tiny purple blemish. Each part

is a blossom under his touch

to which the fibres of her being

stem one by one, each to its end,

until the whole field is a

white desire, empty, a single stem,

a cluster, flower by flower,

a pious wish to whiteness gone over

or nothing.

4 - I Know a Man

Robert Creeley

As I sd to my

friend, because I am

always talking - John, I

sd, which was not his

name, the darkness sur-

rounds us, what

can we do against

it, or else, shall e \&

why not, buy a goddam big car 
drive, se sd, for

christ's sake, look

out where yr going.

\section{IFFERENCIAS HLBLTGRAFICAS}

ELY, Robert. Current poetry in America. The Sixtles, Madison, Minn., (4):28-9. 1960.

The lion's tail and eyes'. Madison, Minn., The Slxties Press, 1962. 45 p. . On English and American poetry. The Flfties, Madison, Minn.. (2):45-7. 1959.

- The possibility of new poctry. The Fifties, Madlson, Minn., (2):36, 1959.

. The work of James Wright. The Slxties, Madison, Minn., (8):67-8, 1960.

. The work of Robert Crecley. The Fifties, Madison, Minn., (2):10-21, 1959.

. A Wrong Turning in American poetry. Choice, Chigago, (3): 33, 47, 1963.

CREELEY, Robert. A quick sraph. San Franciaco, The Four Seasons Foundation. 1970. $365 \mathrm{p}$.

EMERSON, Ralph Waldo. Complete esisay's and other writings. New York, The Modern Librury, 1940, 930 p.

IIALL, Donald. Contemporary American poetry. Rev, ed. Baltimore, Penguin. 1972. $280 \mathrm{p}$.

OLSON, Charles. Sclected writings. New York, New Directions, 1966. 280 p.

POUND, Ezra, Literary essays. New York, New Directions, 1954. 464 p.

SIMIC, Charles. An interview with Charles Simic. Ohlo Review, Athens, 14:47-58, winter 1973.

WIITMANN, Walter. Leaves of grask. Brooklyn, N.Y., 1855. 95 p.

WILLIAMS, William Carlos, Autoblography. New York, Random House ,1951. $402 \mathrm{p}$.

\section{Resumo}

Este artigo trata das duas revoluçōes poéticas ocorridas nas letras norte-americanas no período entre 1913 e 1973. A primeira foi mais uma revoluçāo na técnica poética, em que se procurou libertar a poesia norte-americana da tradição inglesa; passou-se a escrever na língua vernácula, sem rima e sem métrica, e também se buscou conteúdos diferentes. A segunda foi uma revoluçāo no próprio conteúdo poético, buscando-se tanto uma poesia mística e surrealista como uma poesia imagista, destacando-se nesta última a obra de William Carlos Willams.

\section{Summary}

This article deals with the two poctic revolutions which took place in American literature between 1913 and 1973. The first one was mainly a revolution in poetic technique, in which poets tried to free American poetry from the English tradition; they began to writc in the vernacular, disregarding rhyme and metrics, looking also for different subject-matters. The second one was a revolution in the very subject-matter of poetry: experiments were made in mystic, surrealistic and also imagistic poetry, the latter being emphasized by the work of William Carlos Williams. 